\title{
A COMPARATIVE STUDY OF MISOPROSTOL VERSUS SURGICAL MANAGEMENT OF INCOMPLETE AND MISSED ABORTION IN EARLY FIRST TRIMESTER
}

\author{
Vinita Gupta1 ${ }^{1}$ Aastha Aggarwal'2, Shikha Chadha³, Ritu Khatuja4 ${ }^{4}$ Nivedita Sarda 5 , Amrita Anand 6
}

${ }^{1}$ Specialist, Department of Obstetrics and Gynaecology, Dr. Baba Saheb Ambedkar Medical College and Hospital, New Delhi. ${ }^{2}$ Senior Resident, Department of Obstetrics and Gynaecology, Dr. Baba Saheb Ambedkar Medical College and Hospital, New Delhi. ${ }^{3}$ Specialist, Department of Obstetrics and Gynaecology, Dr. Baba Saheb Ambedkar Medical College and Hospital, New Delhi. ${ }_{4}^{4}$ Assistant Professor, Department of Obstetrics and Gynaecology, Dr. Baba Saheb Ambedkar Medical College and Hospital, New Delhi. ${ }_{5}^{5}$ Professor, Department of Obstetrics and Gynaecology, Dr. Baba Saheb Ambedkar Medical College and Hospital, New Delhi. ${ }^{6}$ Secondary DNB, Department of Obstetrics and Gynaecology, Dr. Baba Saheb Ambedkar Medical College and Hospital, New Delhi.

\section{ABSTRACT}

\section{BACKGROUND}

Safe and effective treatment for incomplete abortion is an important way to reduce abortion related morbidity and mortality. Medical methods for treatment of incomplete abortion require few resources, are cost effective and can be administered by low and midlevel providers. Surgical methods are highly effective for treatment of incomplete abortion.

The aim of this study is to compare efficacy of using vaginal Misoprostol for management of incomplete and missed abortion in $\leq 9$ weeks of pregnancy as an alternative to surgical evacuation in our setting and also to assess the patient acceptability and satisfaction for the medical method with surgical method in the same.

\section{MATERIALS AND METHODS}

This is a randomised controlled trial performed on randomly divided 100 patients with missed and incomplete abortion in $\leq 9$ weeks in two groups. On the basis of previous study, the success rate of medical group being $80.7 \%$ and $100 \%$ in surgical group. Group one received Misoprostol tablet $800 \mathrm{mcg}$ single dose per vaginally and second group underwent surgical vaginal evacuation directly under sedation. Both groups were compared in terms of success, complications, pain and patient's satisfaction.

\section{RESULTS}

In medical treatment group, success rates were $92 \%$ as compared to surgical group which had $98 \%$ success rates. Bleeding was more and prolonged in the patients managed by Misoprostol, 36\% patients had moderate bleeding, but no patient required hospitalisation. Though bleeding was less in the surgical group, but all of them required the use of sedation and antibiotics. In the Misoprostol group 56\% were very satisfied, while in surgical group 22\% were moderately satisfied according to VAS score.

\section{CONCLUSION}

Misoprostol is effective in complete evacuation of uterus in both incomplete and missed abortion. It is as effective as surgical evacuation with much more patient satisfaction, especially where demand for services is high, but availability of skilled providers and resources is often scarce.

\section{KEYWORDS}

Incomplete Abortion, Missed Abortion, Misoprostol, Surgical Evacuation.

HOW TO CITE THIS ARTICLE: Gupta V, Aggarwal A, Chadha S, et al. A comparative study of misoprostol versus surgical management of incomplete and missed abortion in early first trimester. J. Evolution Med. Dent. Sci. 2018;7(14):1769-1771, DOI: $10.14260 /$ jemds/2018/399

\section{BACKGROUND}

Approximately, $11 \%-15 \%$ of pregnancies end in spontaneous first trimester miscarriage. ${ }^{1}$ The estimated abortion percentage of known pregnancies was at $21 \%$ worldwide with $26 \%$ in developed countries and $20 \%$ in developing countries. ${ }^{2}$ Amongst these 56 million abortions occurring each year in the world, a little under half are done unsafely.2,3 Unsafe abortions are defined by WHO as abortions performed by people lacking the necessary skills or in an environment that does not fulfil minimal medical standards or both. ${ }^{4,5}$

'Financial or Other Competing Interest': None.

Submission 23-02-2018, Peer Review 20-03-2018,

Acceptance 26-03-2018, Published 02-04-2018.

Corresponding Author:

Dr. Aastha Aggarwal,

H. No. 2, Rd. No. 45A, West Avenue Road,

Punjabi Bagh (West). New Delhi-110026.

E-mail: aasthagg84@gmail.com

DOI: $10.14260 /$ jemds $/ 2018 / 399$
Unsafe abortions cause 47,000 deaths and 5 million hospital admissions each year.6,7 Safe and effective treatment for incomplete abortion is an important way to reduce abortion related morbidity and mortality. Medical methods for treatment of incomplete abortion require few resources, are cost effective and can be administered by low and midlevel providers. Surgical methods are highly effective for treatment of incomplete abortion. However, these treatments require trained providers, special equipment, sterile conditions and often anaesthesia. All of these are limited in many settings. Therefore, this study was done to compare efficacy of medical management of incomplete and missed abortion with surgical evacuation in $\leq 9$ weeks of pregnancy as well as comparison of the side effects and complications between the two methods.

\section{MATERIALS AND METHODS}

The present study was randomised controlled trial conducted in the Department of Obstetrics and Gynaecology, Dr. Baba Saheb Ambedkar Hospital, Rohini, New Delhi, during the period of November 2014 to May 2015. This is a prospective comparative study performed on 100 patients with first trimester incomplete and missed miscarriage $\leq 9$ weeks. 
On the basis of various studies, the success rate of medical group being $80.7 \%$ (95\%, CI: 69.97 - 91.43) and surgical group being $100 \%$, the minimum required sample size with $90 \%$ power of study and $5 \%$ level of significance was calculated to be 44 subjects in each group. Thus, to lower the margin of error, 100 subjects were selected (50 in each group). They were divided into two groups randomly. It was done on the basis of computerised block randomisation.

1. Received Misoprostol tablet $800 \mathrm{mcg}$ single dose per vaginally.

2. Underwent surgical vaginal evacuation directly under sedation.

Patients included in this study were those which were haemodynamically stable and diagnosed with incomplete or missed abortion clinically and by ultrasonography with GA $\leq$ 9 weeks, retained products of conception of $>1.5 \mathrm{~cm}$ in ultrasonography and those who were willing for follow-up after 15 days.

In this study, the patients which were excluded were those diagnosed with gestational age $>9$ weeks, threatened abortion, patients with active bleeding, haemodynamically unstable, having signs of infection, known allergy to prostaglandins, medical illness contraindicating the use of prostaglandins, severe anaemia $(\mathrm{Hb}<7 \mathrm{gm} \%)$, previous 3 LSCS or previous h/o uterine rupture and suspected ectopic pregnancy.

\section{Methodology}

Patients admitted with complaints of amenorrhoea followed by bleeding

Diagnosis of incomplete or missed abortion was confirmed by clinical and ultrasonography findings. Routine investigations done

$$
\downarrow
$$

After applying exclusion criteria, patients were divided into 2 groups (randomly)

$\downarrow$

Group A- 800 mcg Misoprostol vaginally

Group B- Evacuation under sedation and antibiotics

$\downarrow$

Follow-up after 15 days.

In follow-up, USG was done to confirm complete evacuation of the retained products. Also amount of bleeding, sepsis, pain, requirement for re-evacuation and further interventions like blood transfusion and hospitalisation were assessed by a detailed proforma. Success of any method was defined as complete evacuation of products of conception by an ultrasound and absence of any clinical symptoms. Patient's satisfaction and acceptability were evaluated on the basis of discomfort/ abdominal pain, duration and amount of vaginal bleeding and requirement of hospital admission. This was noted on VAS (Visual Analogue Scale). ${ }^{8}$

\section{Statistical Analysis}

In this study VAS score was compared using unpaired t-test, while qualitative variables were compared using Chi-square test/ Fisher's exact test. A p-value $<0.05$ was considered statistically significant.

\section{RESULTS}

All the women belonged to low socioeconomic status. Distribution of cases were comparable in both the groups (Table 1).

\begin{tabular}{|c|c|c|c|c|}
\hline \multirow{2}{*}{ Cases } & \multicolumn{2}{|c|}{ Medical (n= 50) } & \multicolumn{2}{c|}{ Surgical (n= 50) } \\
\cline { 2 - 5 } & No. & $\mathbf{\%}$ & No. & $\mathbf{\%}$ \\
\hline Incomplete & 12 & 24 & 15 & 30 \\
\hline Missed & 38 & 76 & 35 & 70 \\
\hline Total & $\mathbf{5 0}$ & $\mathbf{1 0 0}$ & $\mathbf{5 0}$ & $\mathbf{1 0 0}$ \\
\hline \multicolumn{3}{|c}{ Table 1. Distribution of Cases } \\
\hline
\end{tabular}

In the present study $24 \%$ patients in medical group and $30 \%$ patients in surgical group were incomplete cases, while $76 \%$ patients in medical group and $70 \%$ patients in surgical group were missed abortions. In both groups, age and parity of women were comparable.

In medical group 92\% success rates were obtained, while in surgical group it was $98 \%$ which had no statistical significant difference $(p>0.005)$ and thus were comparable. The incidences of side effects were more in medical group and statistically significant. The numbers of patients with post-abortal bleeding were more in the medical group. It was statistically correlated and found to be significant ( $\mathrm{p}$ value < 0.005). All women required sedation and antibiotic in surgical group, whereas no sedation was given in medical group and two women were given antibiotics due to prolonged bleeding. Surprisingly, no patient required a reevacuation in both the groups. There was no perforation in the surgical group (Table 2).

\begin{tabular}{|c|c|c|c|c|}
\hline \multirow{2}{*}{ Outcome } & \multicolumn{2}{|c|}{ Medical } & \multicolumn{2}{c|}{ Surgical } \\
\cline { 2 - 5 } & No. & $\mathbf{\%}$ & No. & $\mathbf{\%}$ \\
\hline Success of treatment method & 46 & 92 & 49 & 98 \\
\hline Incidence of side effects & 43 & 86 & 8 & 16 \\
\hline $\begin{array}{c}\text { Incidence of excessive post abortive } \\
\text { bleeding }\end{array}$ & 18 & 36 & 1 & 2 \\
\hline \multicolumn{5}{|c|}{ Table 2. Clinical Outcome of the Study Group } \\
\hline
\end{tabular}

The mean of VAS score (patient's satisfaction level) in medical group was 4.28, whereas in surgical group it was only 2.76 ( $\mathrm{p}<0.0005)$ which was statistically significant. Medical group patients were highly satisfied as compared to surgical group (Table 3).

\begin{tabular}{|c|c|c|c|c|c|}
\hline \multirow{2}{*}{$\begin{array}{c}\text { VAS } \\
\text { Score }\end{array}$} & \multicolumn{2}{|c|}{$\begin{array}{c}\text { Medical } \\
\text { (n= 50) }\end{array}$} & \multicolumn{2}{c|}{$\begin{array}{c}\text { Surgical } \\
\text { (n= 50) }\end{array}$} & \multirow{2}{*}{ Total } \\
\cline { 2 - 5 } & No. & $\mathbf{\%}$ & No. & $\mathbf{\%}$ & \\
\hline 1 & 4 & 8 & 4 & 8 & 8 \\
\hline 2 & 0 & 0 & 15 & 30 & 15 \\
\hline 3 & 1 & 2 & 20 & 40 & 21 \\
\hline 4 & 17 & 34 & 11 & 22 & 28 \\
\hline 5 & 28 & 56 & 0 & 0 & 28 \\
\hline Total & $\mathbf{5 0}$ & $\mathbf{1 0 0}$ & $\mathbf{5 0}$ & $\mathbf{1 0 0}$ & $\mathbf{1 0 0}$ \\
\hline \multicolumn{6}{|c|}{ Table 3. Patient's Satisfaction (VAS) } \\
\hline
\end{tabular}

\section{DISCUSSION}

Medical and surgical methods are the only treatments to be used for incomplete and missed abortion. In medical treatment according to the recommendations by FIGO in $<13$ weeks gestation of missed abortion, $800 \mathrm{mcg}$ Misoprostol is 
given per vaginally (P/V) every 3 hours (2 doses) or $600 \mathrm{mcg}$ sublingual (S/L) every 3 hours (2 doses) and for incomplete abortion it is single dose misoprostol of $600 \mathrm{mcg}$ orally or $400 \mathrm{mcg} \mathrm{S} / \mathrm{L}$ or $400-800 \mathrm{mcg}$ P/V. ${ }^{9}$ But in our study as women were of low socioeconomic status, they were likely to be lost for follow-up. Therefore, we had used single dose of Misoprostol for both missed and incomplete abortion.

Success rate in both groups were comparable and no statistical significant difference was found between the two groups $(p>0.005)$. High success rates have been found in many studies, which also showed no statistical significant difference between the two methods in $1^{\text {st }}$ trimester abortion as in our study. ${ }^{10,11,12}$

In present study, the number of women with post abortal bleeding were more in the medical group. It was statistically correlated and found to be significant ( $p$ value $<0.005$ ). Many studies conducted indicate similar results to our study.13,14 No patients in both the groups underwent surgical re-evacuation later or any blood transfusion.

In our study the mean of VAS score (patient's satisfaction level) in medical group was 4.28 , whereas in surgical group it was only $2.76(\mathrm{p}<0.0005)$ which was significant. Comparable results were found in other studies, where patient's satisfaction level was more in medical than the surgical group and was statistically significant.10,15,16 Despite that in medical group more side effects and excessive post abortal bleeding was noticed, it was well tolerated in comparison to surgical group.

Professional associations such as the American College of Obstetricians and Gynaecologists recommend Misoprostol for post-abortion care and the World Health Organisation has added Misoprostol for the management of incomplete abortion and miscarriage to its Model List of Essential Medicines. ${ }^{17}$

The available Cochrane systematic review evidence suggest that expectant care as well as medical treatment with Misoprostol are acceptable alternatives to routine vaginal surgical evacuation. ${ }^{18}$

Despite the fact that so many studies prove the benefits of medical treatment, the services go unreached to many strata of population owing to the widespread illiteracy and the unmet availability of resources and trained personnel, that many are lost for follow-up as well as availability of Misoprostol over-the-counter in our country has led to misuse of this wonder drug.

\section{Limitations}

This study was done on a small and restricted population group. Studies are required which include larger groups with diverse population strata.

\section{CONCLUSION}

Given its safety, efficacy and ease of use, misoprostol is an important option for the treatment of women with incomplete abortion. It is the need of hour that widespread resources and services be provided to overcome all the associated obstacles in decreasing maternal morbidity and mortality.

\section{REFERENCES}

[1] Steer C, Campbell S, Davies M, et al. Spontaneous abortion rates after natural and assisted conception. BMJ 1989;299(6711):1317-8.
[2] Sedgh G, Singh S, Shah IH, et al. Induced abortion: incidence and trends worldwide from 1995 to 2008. The Lancet 2012;379(9816):625-32.

[3] Sedgh G, Bearak J, Singh S, et al. Abortion incidence between 1990 and 2014: global, regional and subregional levels and trends. The Lancet 2016;388(10041):258-67.

[4] Grimes DA, Benson J, Singh S, et al. Unsafe abortion: the preventable pandemic. The Lancet 2006;368(9550):1908-19.

[5] Singh S. Hospital admissions resulting from unsafe abortion: estimates from 13 developing countries. Lancet 2006;368(9550):1887-92.

[6] Lohr PA, Fjerstad M, DeSilva U, et al. Abortion. BMJ 2014;348:f7553.

[7] Shah I, Ahman E. Unsafe abortion: global and regional incidence, trends, consequences, and challenges. J Obstet Gynaecol Can 2009;31(12):1149-58.

[8] Hasson D, Arnetz BB. Validation and findings comparing VAS vs. Likert scales for Psychosocial measurements. International Electronic Journal of Health Education 2005;8:178-92.

[9] Morris JL, Winikoff B, Dabash R, et al. FIGO's updated recommendations for Misoprostol used alone in Gynecology \& Obstetrics. Int J Gynecol Obstet 2017;138(3):363-6.

[10] Wood SL, Brain PH. Medical management of missed abortion: a randomized clinical trial. Obstet Gynecol 2002;99(4):563-6.

[11] Zhang J, Gilles JM, Barnhart K, et al. A comparison of medical management with misoprostol and surgical management for early pregnancy failure. $\mathrm{N}$ Engl J Med 2005;353(8):761-9.

[12] Moodliar S, Bagratee JS, Moodley J. Medical vs. surgical evacuation of first-trimester spontaneous abortion. Int J Gynaecol Obstet 2005;91(1):21-6.

[13] Tang OS, Lau WNT, Ng EH, et al. A prospective randomized study to compare the use of repeated doses of vaginal with sublingual misoprostol in the management of first trimester silent miscarriages. Hum Reprod 2003;18(1):176-81.

[14] Bagratee JS, Khullar V, Regan L, et al. A randomized controlled trial comparing medical and expectant management of first trimester miscarriage. Hum Reprod 2004;19(2):266-71.

[15] Demetroulis C, Saridogan E, Kunde D, et al. A prospective randomized control trial comparing medical and surgical treatment for early pregnancy failure. Hum Reprod 2001;16(2):365-9.

[16] Chung TK, Cheung LP, Sahota DS, et al. Spontaneous abortion: short-term complications following either conservative or surgical management. Aust $\mathrm{N} \mathrm{Z} \mathrm{J}$ Obstet Gynaecol 1998;38(1):61-4.

[17] Unedited draft report of the $17^{\text {th }}$ Expert Committee on the Selection and Use of Essential Medicines. Geneva, Switzerland: World Health Organization, 2009.

[18] Neilson JP, Gyte GM, Hickey M, et al. Medical 226 treatments for incomplete miscarriage (less than 24 weeks). Cochrane Database Syst Rev 2010;(1):CD007223. 